\title{
Editorial
}

\section{Bonebridge Bone Conduction Implant}

\author{
Ricardo Ferreira Bento ${ }^{1}$ Paula Tardim Lopes ${ }^{1}$ Francisco da Chagas Cabral Junior ${ }^{1}$ \\ ${ }^{1}$ Department of Otorhinolaryngology, Universidade de São Paulo, \\ School of Medicine, São Paulo, SP, Brazil \\ Int Arch Otorhinolaryngol 2015;19:277-278.
}

In this issue, we have an interesting review article by Dr. Mario Zernotti and his team in Cordoba on the Bonebridge bone conduction implant.

Bone conduction implants are indicated for patients with conductive, mixed, or unilateral hearing loss. The transcutaneous technology employed avoids common complications such as cutaneous reactions, skin covering the abutment, local infection, or extrusion.

The aim of this systematic review was to evaluate the hearing gain through speech perception tests and word recognition scores in 20 patients implanted with the Bonebridge device. Furthermore, the authors analyze the functioning of this bone conduction implant, as well as three possible surgical techniques. ${ }^{1}$

The Bonebridge is the first active bone conduction implant system in the world. It is a semi-implantable device consisting of a sound processor and a coil that generate vibration in the bone, transmitted through screws fixed to the mastoid. The system for securing the screws to the bone does not require osseointegration and should be activated within two to three weeks after implantation.

The use of this implant is indicated for children older than five years of age, with conductive or mixed hearing loss according to audiometric tests, and bone conduction threshold above $45 \mathrm{~dB}$ at $500 \mathrm{~Hz}$, and 1, 2, and $3 \mathrm{KHz}$. The contraindications in these cases are related to the presence of retrocochlear lesions. As for unilateral hearing losses, the use of this implant is indicated when this condition is severe or profound in one ear, while the other presents a bone conduction threshold above $20 \mathrm{~dB}$ from $500 \mathrm{~Hz}$ to 3 $\mathrm{KHz}^{2}$

Before the surgery, the patient should undergo a radiological tomography with tridimensional analysis to determine the exact location where the implant should be placed, thus preventing possible complications. ${ }^{3,4}$

In cases where it is not possible to place the implant on the mastoid because either the sigmoid sinus is too anterior, the dura mater in the middle cranial fossa is too low, or the patient has undergone mastoidectomy previously, the suggested routes for implant placement are through the retrosigmoid or the middle fossa. In these cases, the exposure of the dura mater with its depression for the positioning of the bone conduction floating mass transducer (BC-FMT) does not lead to any sequelae. ${ }^{5,6}$

Nevertheless, this technique has a few disadvantages. First, surgery requires more extensive drilling, and can lead to lesions in the dura mater and sigmoid sinus that should be managed with synthetic hemostatic materials or sutures. Besides, there is risk of necrosis or local infection, which can be decreased by performing a double flap, which provides better vascularization than a simple incision. $2,7,8$

In the systematic review in question, conducted between May 2012 and July 2014, the initial search in MedLine identified 19 studies; however, only five described the surgical technique employed. Thus, these were included in the study, involving 20 patients with different pathologies. In the authors' experience, $90 \%$ of patients with conductive hearing loss showed a reduction of 30 to $60 \mathrm{~dB}$ in the airbone gap after implant placement. This finding is in line with the results reported in the studies included in this systematic review, where the functional gain varied between 24 and $43 \mathrm{~dB}$, and in $50 \%$, functional gain was greater than $30 \mathrm{~dB}{ }^{9}$

Finally, we have concluded that the Bonebridge implant is an innovative solution for patients with conductive or mixed hearing loss and unilateral loss, who did not show good response to other forms of treatment. Different surgical techniques can be used for implant placement, depending on the patient's anatomy. Studies show higher functional gain, better speech perception, and lower rates of percutaneous complications associated with this implant.

\section{References}

1 Zernotti ME, Sarasty AB. Active Bone Conduction Prosthesis: Bonebridge $^{\mathrm{TM}}$. Int Arch Otorhinolaryngol 2015;19(4):343-348
Address for correspondence Paula Tardim Lopes, MD, Departamento de Otorrinolaringologia do Hospital das Clínicas da Faculdade de Medicina da USP, Av. Dr. Enéas de Carvalho Aguiar, 255, $6^{\circ}$ andar, sala 6167, São Paulo, SP, Brazil 05403-000 (e-mail: paulatardimlopes@gmail. com).
DOI http://dx.doi.org/ 10.1055/s-0035-1564567. ISSN 1809-9777.
Copyright $\odot 2015$ by Thieme Publicações License terms Ltda, Rio de Janeiro, Brazil 
2 Badran K, Arya AK, Bunstone D, Mackinnon N. Long-term complications of bone-anchored hearing aids: a 14-year experience. J Laryngol Otol 2009;123(2):170-176

3 Güldner C, Heinrichs J, Weiß R, et al. Visualisation of the Bonebridge by means of CT and CBCT. Eur J Med Res 2013; 18(1):30

4 Canis M, Ihler F, Blum J, Matthias C. [CT-assisted navigation for retrosigmoidal implantation of the Bonebridge]. HNO 2013; 61(12):1038-1044

5 Lassaletta L, Sanchez-Cuadrado I, Muñoz E, Gavilan J. Retrosigmoid implantation of an active bone conduction stimulator in a patient with chronic otitis media. Auris Nasus Larynx 2014;41(1): 84-87
6 da Costa SS, Rosito LP, Dornelles C. Sensorineural hearing loss in patients with chronic otitis media. Eur Arch Otorhinolaryngol 2009;266(2):221-224

7 Ricci G, Della Volpe A, Faralli M, et al. Results and complications of the Baha system (bone-anchored hearing aid). Eur Arch Otorhinolaryngol 2010;267(10):1539-1545

8 Hobson JC, Roper AJ, Andrew R, Rothera MP, Hill P, Green KM. Complications of bone-anchored hearing aid implantation. J Laryngol Otol 2010;124(2):132-136

9 Sprinzl G, Lenarz T, Ernst A, et al. First European multicenter results with a new transcutaneous bone conduction hearing implant system: short-term safety and efficacy. Otol Neurotol 2013;34(6):1076-1083 